\title{
Ultrahigh Resolution Marine Magnetic Anomaly Profiles: A Record of Continuous Paleointensity Variations?
}

\author{
STEVEN C. CANDE ${ }^{1}$ AND DENNIS V. KENT
}

\author{
Lamont-Doherty Geological Observatory of Colwmbia University, Palisades, New York
}

\begin{abstract}
A distinctive pattern of small-scale marine magnetic anomalies (25-100 nT amplitude, 8-25 km wavelength tiny wiggles) is superimposed on the more generally recognized seafloor spreading pattem between anomalies 24 and 27 in the Indian Ocean. By normalizing and stacking multiple profiles, it is demonstrated that this pattern of tiny wiggles is a high-resolution recording of paleodipole field behavior between chrons $\mathrm{C} 24$ and C27. The pattern of tiny wiggles between anomalies 26 and 27 is compared to an ultrafast spreading $(82 \mathrm{~mm} / \mathrm{yr}$ half rate) profile from the southeast Pacific where a similar signal is observed, confirming the paleodipole field origin of the anomalies. Two basic models are considered in which the tiny wiggles are attributed either to short polarity intervals or to paleointensity fluctuations. We conclude that tiny wiggles are most likely caused by paleointensity fluctuations of the dipole field and are a ubiquitous background signal to most fast spreading magnetic profiles. The implications of this study are that (1) tiny wiggles may provide information on the temporal evolution of the geomagnetic dynamo; (2) the small-scale anomalies observed in the Jurassic quiet zones may be due to paleointensity fluctuations; (3) tiny wiggles are potential time markers in large regions of uniform crustal polarity such as the Cretaceous quiet zones; and (4) much of the variance in anomaly profiles normally attributed to crustal emplacement processes, particularly at fast and ultrafast spreading rates, is actually due to intensity variations in the paleomagnetic field.
\end{abstract}

\section{INTRODUCTION}

Occasional short polarity intervals, in addition to those originally identified by Heirtzler et al. [1968] in their magnetic polarity time scale, have been documented in detailed studies of marine magnetic anomaly data [e.g., Blakely and Cox, 1972; Blakely, 1974; Rea and Blakely, 1975; Wilson and Hey, 1981; Cande and Kent, 1992]. Marine magnetic surveys of fast spreading (> $50 \mathrm{~mm} / \mathrm{yr}$ half rate) oceanic crust, however, often reveal a continuous pattern of small amplitude, linear magnetic anomalies superimposed on the more generally recognized seafloor spreading anomaly pattern [Cande and LaBrecque, 1974]. The origin of these small-scale anomalies, which are referred to as "tiny wiggles" [LaBrecque et al., 1977], has been controversial. Blakely [1974] and Cande and LaBrecque [1974] proposed that small-scale anomalies represent a high-resolution recording of the Earth's paleomagnetic field behavior, either short polarity events or paleointensity variations, whereas Schouten and Denham [1979] argued that they are caused by local variations in the magnetization of the source layer. The resolution of this question has important implications both for the nature of the geomagnetic field and for the structure of the magnetized layer.

There are two critical questions we address in this paper. A fundamental issue is whether tiny wiggles are actually a recording of paleomagnetic field behavior or, alternatively, if they are simply due to local variations in the magnetic source layer. If the former, the second question is whether they are caused by complete reversals of the field or, alternatively, reflect some other aspect of the paleomagnetic field such as paleointensity fluctuations.

We proceed by first analyzing magnetic anomalies over the Indian Ocean generated during a period of rapid seafloor spreading in the early Cenozoic [Patriat, 1983]. We find a very distinctive and coherent pattern of tiny wiggles superimposed on the long reversed intervals between anomalies 24 and 27 . A stack of profiles from several different areas of the Indian Ocean supports their field related origin. We also show that the same distinctive signal between anomalies 26 and 27 is observed

\footnotetext{
1Now at Scripps Institution of Oceanography, La Jolla, CA.
}

Copyright 1992 by the American Geophysical Union.

Paper number 92JB01090.

0148-0227/92/92JB-01090\$05.00 over fast spreading oceanic crust several thousand kms distant in the southeast Pacific. Thus we conclude that these anomalies represent a remarkably high fidelity recording of the Earth's dipole magnetic field during the Paleocene.

We then demonstrate through a modeling exercise that the tiny wiggles are not likely due to complete reversals of the field and, instead, appear to be due to intensity variations of the paleodipole field. We show that they may be due to the same spectrum of intensity fluctuations of the dipole field that are recognized over the last $5 \mathrm{Ma}$ from paleointensity studies [e.g., Merrill and McElhinny, 1983].

The recognition of tiny wiggles in the early Cenozoic suggests that the dipole field intensity fluctuations responsible for them may be a normal background aspect of the geomagnetic dipole field recorded by the ocean crust. We propose that a more complete model of the texture of the magnetic source layer, particularly when modeling the character of fast spreading anomalies, should include not only temporal and spatial variations in the extrusion process as suggested by Schouten and Denham [1979], but also magnetization fluctuations due to paleointensity variations.

\section{Data From the Central Indian Ocean}

High fidelity recordings of the Earth's magnetic field require a combination of fast spreading rates, uniform plate motion, and a favorable orientation relative to Earth's magnetic field. The Central Indian Ocean was characterized by these three conditions in the Paleocene. Starting in the late Cretaceous, spreading rates accelerated on the Central Indian Ridge to a half rate of over $60 \mathrm{~mm} / \mathrm{yr}$ at around anomaly 30 time [Patriat, 1983]. Major adjustments in spreading occurred between anomalies 30 and 28 as the ridge axis jumped from the Mascarene basin to the north side of the Seychelles. Around anomaly 24 time India started to collide with Asia and spreading slowed down and changed direction. The interval between anomalies 27 and 24, however, marked a period of uniform fast spreading when particularly distinct patterns of tiny wiggles were recorded by the oceanic crust.

We have analyzed 21 magnetic profiles crossing anomalies 24 to 27 in the Indian Ocean (Figure 1), encompassing the time interval between 62 and $53 \mathrm{Ma}$ according to the time scale of Cande and Kent [1992]. The profiles come from five distinct geographical regions: north of the Seychelles on the south flank of the Carlsberg Ridge, southeast of Madagascar in the Madagascar Basin, in the Crozet Basin, south of India in the Indian Basin, and east of the Ninety-East Ridge in the Wharton 


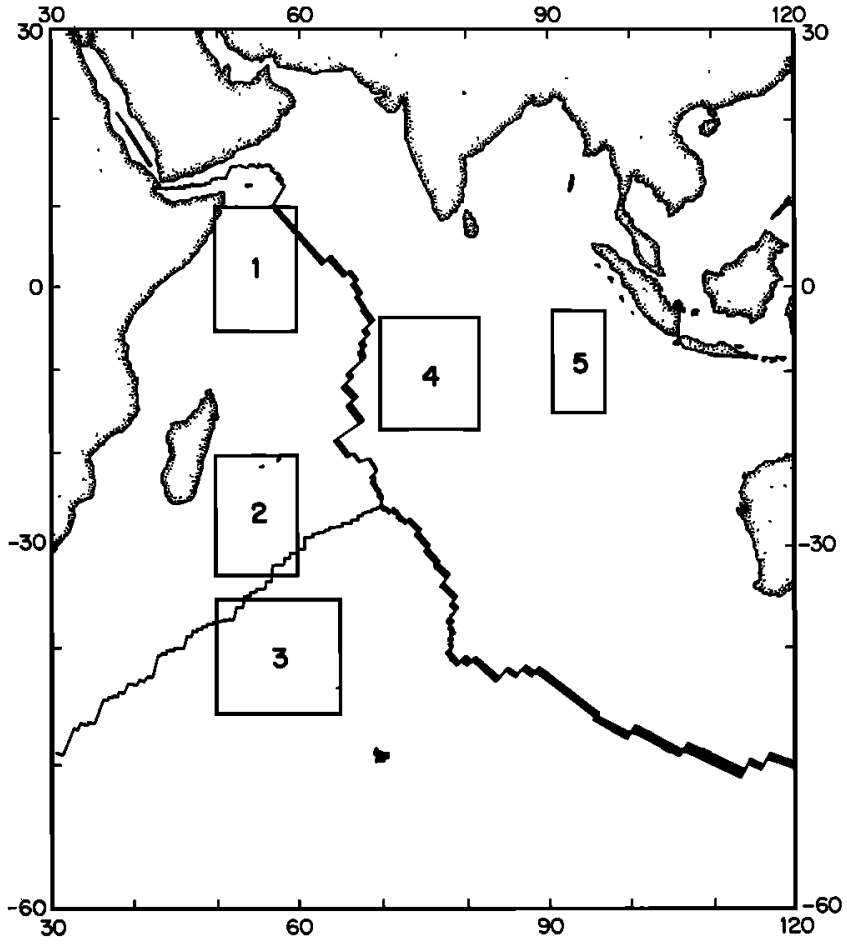

Fig 1. Location of detailed maps shown in Figure 2.

Basin. Thus the profiles together reflect spreading on ridges separating Africa from Indian and India from Antarctica. The locations of the profiles relative to the regional magnetic anomaly pattern are shown in the detailed tectonic maps in Figure 2. The profiles were carefully selected to avoid anomalous topographic features and fracture zones. The data consist primarily of magnetic profiles collected by U.S. and French research vessels over the last 25 years.

An examination of the profiles in Figure 3 reveals a pattern of small scale anomalies, with amplitudes of 25 to $100 \mathrm{nT}$ and wavelengths of 8 to $25 \mathrm{~km}$, between the larger magnetic anomalies attributed to recognized magnetic reversals.

\section{ANALYSIS}

In order to determine if there is a coherent pattern of smallscale anomalies at different geographical regions in the Indian Ocean, the profiles were reduced to the pole, stretched to a common width, and stacked [Blakely and Cox, 1972]. The reduction to the pole process removes the anomaly skewness or shape asymmetry [Schouten, 1971] due to the variable strike of the lineations and the variable direction of the remanent and present day field vectors at the different sites. Accordingly, we calculated theoretical skewness and amplitude values for each profile using the formulation of Schouten and McCamy [1972], and then inverse phase filtered the profiles and normalized the amplitudes. A Paleocene pole for the African plate of latitude $70.1^{\circ} \mathrm{N}$ and longitude $213.0^{\circ} \mathrm{E}$ [Schneider and Kent, 1990] was used to calculate the skewness and amplitude parameters for profiles on the African plate. The finite rotation parameters of Royer and Coffin [1992] for the relative motion of Antarctica to Africa at anomaly $26 \mathrm{r}$ time $\left(3.8^{\circ} \mathrm{N}, 39.7^{\circ} \mathrm{W},-10.63^{\circ}\right)$ and Molnar et al. [1988] for the relative motion of India to Africa at anomaly 25 time $\left(22.79^{\circ} \mathrm{N}, 26.56^{\circ} \mathrm{E}, 39.88^{\circ}\right)$ were used in conjunction with the Schneider and Kent [1990] pole to calculate the skewness and amplitude parameters for the other profiles.

We divided the interval from anomaly 24 to anomaly 27 into three separate segments (anomaly 24 to 25,25 to 26 and 26 to 27). The profiles for each segment were stretched to a uniform distance between the major positive anomalies bounding each of the long intervals of reversed polarity. The stretching points were determined in a separate procedure by bandpassing and downward continuing the deskewed (inverse phase filtered) profiles and then fitting a boxcar function to the zero crossings of the profiles. The reduced-to-the-pole profiles were then stacked for each of the three segments and are shown in Figures 4,5 , and 6 .

Before examining the tiny wiggles, it is interesting to first examine the residual skewness of the stacked profiles. It has been observed that many marine magnetic profiles, after being reduced to the pole, display a residual skewness or anomalous skewness [Cande, 1976]. The cause of anomalous skewness is uncertain, although several different mechanisms have been proposed. Possible mechanisms include tectonic rotation of the source layer [Verosub and Moores, 1981], contributions from deeper layers in which the acquisition of magnetization is delayed [Cande and Kent, 1976], the overprinting effects of chemical remanent magnetization [Raymond and LaBrecque, 1987] or thermoviscous remanent magnetization [ArkaniHamed, 1989], or systematic, long-period variations in the intensity of the dipole field [Cande, 1978].

It is evident from Figures 4, 5, and 6 that, although individual profiles occasionally have residual skewness, the stacked (averaged) profiles from the Indian Ocean are within $5^{\circ}$ of theoretical symmetry and display very little if any anomalous skewness. The virtual lack of anomalous skewness in the Indian Ocean profiles suggests that the magnetic source at this fast spreading rate is relatively simple, without the obvious complexities observed at slower spreading rates, and may explain why tiny wiggles are particularly well recorded in this region.

The only other skewness observations for this time interval are by Petronotis et al. [1989], who observed about $11^{\circ}$ of anomalous skewness in anomaly $25 \mathrm{r}$ in slower spreading rate $(-30 \mathrm{~mm} / \mathrm{yr})$ profiles from the Pacific. This result is consistent with previous findings of an apparent spreading rate dependency for the magnitude of anomalous skewness: for the same anomaly, faster spreading rate profiles generally have less anomalous skewness than slower spreading rate profiles [Cande, 1978; Roest et al., 1992]. The implication of this spreading rate dependency is subject to debate, since the cause of anomalous skewness itself is still unclear, but it supports conventional wisdom that the magnetic source layer at faster spreading rates is less complex than at slower spreading rates.

We now tum to the tiny wiggles. For each time interval a distinctive pattern of small-scale anomalies is observed in both the individual profiles and in the stacked profiles: over the $\mathbf{2 . 8}$ Ma interval between anomalies 24 and 25 , we recognize a pattern of 10 tiny wiggles (Figure 4); a pattern of five tiny wiggles in the $1.2 \mathrm{Ma}$ interval between anomalies 25 and 26 (Figure 5); and a pattern of seven tiny wiggles in the $3.0 \mathrm{Ma}$ interval between anomalies 26 and 27 (Figure 6). One can argue with the individual picks for each stack, but we maintain that the overall pattern is well represented by our particular selection.

The tiny wiggle patterns observed between anomalies 24 and 27 are not as obviously coherent as the tiny wiggle pattern observed within anomaly 5 [Blakely, 1974; Cande and LaBrecque, 1974]. However, we believe that this is a reflection of the difference in the data coverage rather than a difference in the fundamental source of the tiny wiggles. The tiny wiggles observed within anomaly 5 were principally documented on profiles from the region of the 1971 National Oceanic and Atmospheric Administration (NOAA) SurveyorSEAMAP survey off the coast of Washington and Oregon. The data shown by Blakely [1974] and Cande and LaBrecque [1974] are from closely spaced lines, collected as part of a uniform survey and sampling essentially a single spreading corridor on the west flank of the Juan de Fuca ridge. In comparison, the lines in Figures 4, 5, and 6 are from widely separated regions of the Indian Ocean (Figure 1), sampling several different 

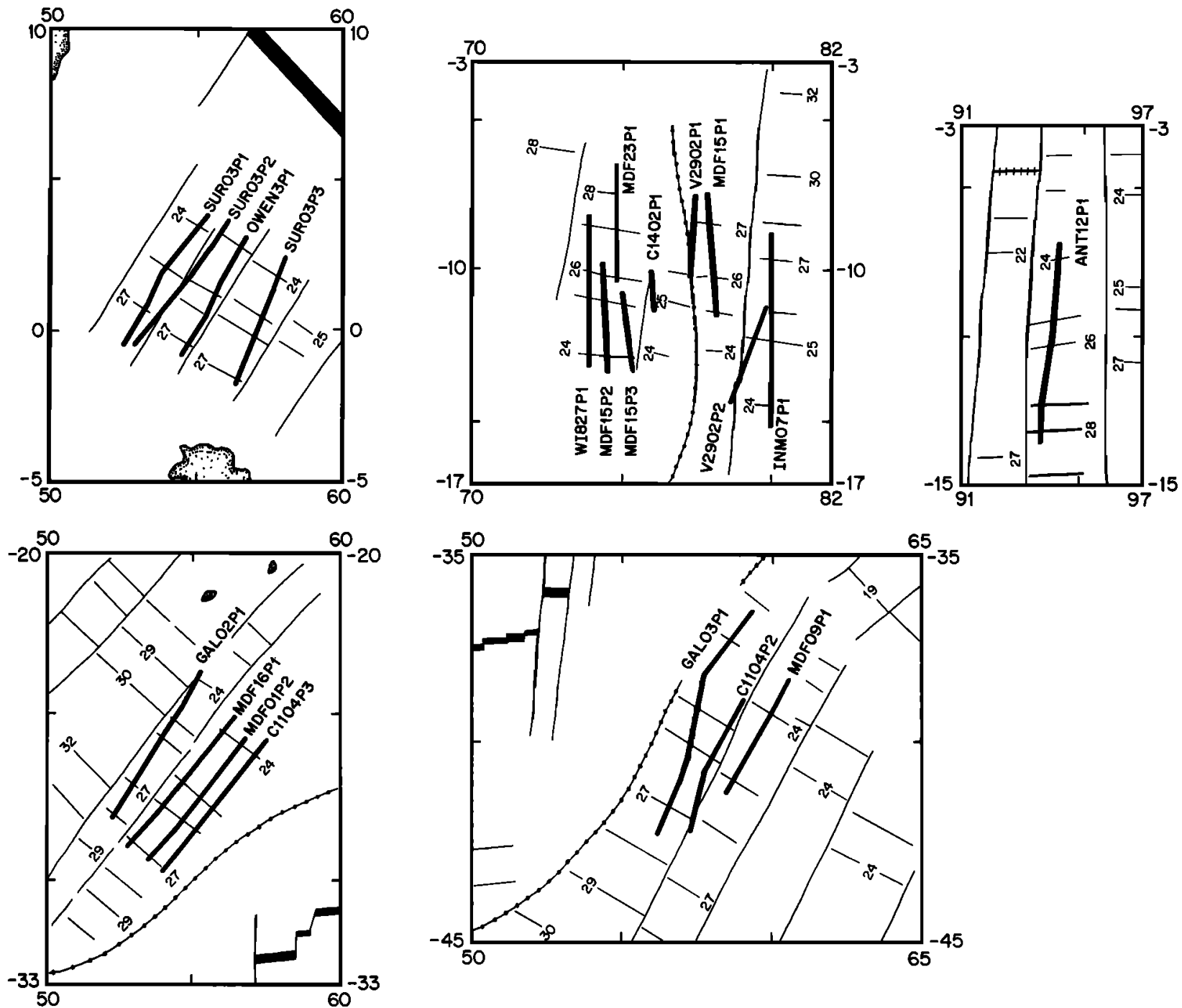

Fig. 2. Detailed maps showing location of magnetic profiles from the Indian Ocean used in this study. Cruise identifications are as follows: prefix C: R/V Conrad; V: R/V Vema; GAL: Gellieni; MDF: Marion Dufresne; SUR: Suroit; INM and ANT: R/V Washington; WI: USNS Wilkes.

spreading corridors on two ldifferent ridge systems (Figure 2). These widely separated lines may very well reflect slightly different tectonic histories, perhaps caused by small ridge jumps or unmapped propagators, that will degrade the quality of the stack and obscure the coherence of the field-related signal.

The lack of an ideal data set was apparent when we attempted to rigorously demonstrate the coherence of the tiny wiggles between anomalies 24 and 27 using a test suggested by Schouten and Denham [1979] in which the the variance of the stack of observed profiles is compared to the variance expected for a stack of random profiles. The results were ambiguous, a fact that we attribute to small lateral displacements of the anomalies caused by minor ridge jumps and navigation errors. In fact, careful scrutiny of the profiles in Figures 4, 5, and 6 reveals several small offsets that, if compensated for, would enhance the variance of the stack. Although a stack may work well on closely spaced lines collected as part of a uniform survey in a limited region [e.g., Blakely, 1974], in many areas where we would most like to search for tiny wiggles, such uniform coverage does not presently exist.

\section{Comparison With Profiles From Other Oceans}

An additional test of the paleomagnetic field origin is to search for the same distinctive pattern in other oceans. A classical area to look for tiny wiggles is in the North Pacific [Blakely and Cox, 1972]. In Figure 7 (bottom) we show a representative deskewed profile (P7103) across anomalies 26 and 27 between the Murray and Mendocino FZs. With a spreading rate $(31 \mathrm{~mm} / \mathrm{yr})$ that is only $57 \%$ of the rate in the Indian Ocean, the resolution of tiny wiggles in the North Pacific is much less than in the Indian Ocean. Only two or three broad variations are observed between anomalies 26 and 27 as compared to the eight distinctive small-scale anomalies observed on the representative profile (MDF23P1) from the Indian Ocean (Figure 7, center). This large apparent decrease in resolution may explain why Blakely and Cox [1972] were not able to recognize any correlatable short polarity intervals in the North Pacific in this time interval.

The fastest known spreading ridge in the Paleocene was a short (roughly $100 \mathrm{~km}$ wide) section of the mid-ocean ridge system between the Pacific and Aluk plates in the South Pacific. A small $(100 \mathrm{~km}$ by $300 \mathrm{~km})$ piece of the Pacific Plate that formed at the Pacific-Aluk Ridge was broken off at anomaly 21 time and became attached to the Antarctic Plate. A record of anomalies 26 to 27 , generated at a half rate of roughly $82 \mathrm{~mm} / \mathrm{yr}$, is found on this piece of crust [Cande et al., 1982]. A representative deskewed profile (C2107) over the fast spreading Pacific-Aluk crust between anomalies 26 and 27 is shown in the top of Figure 7. 

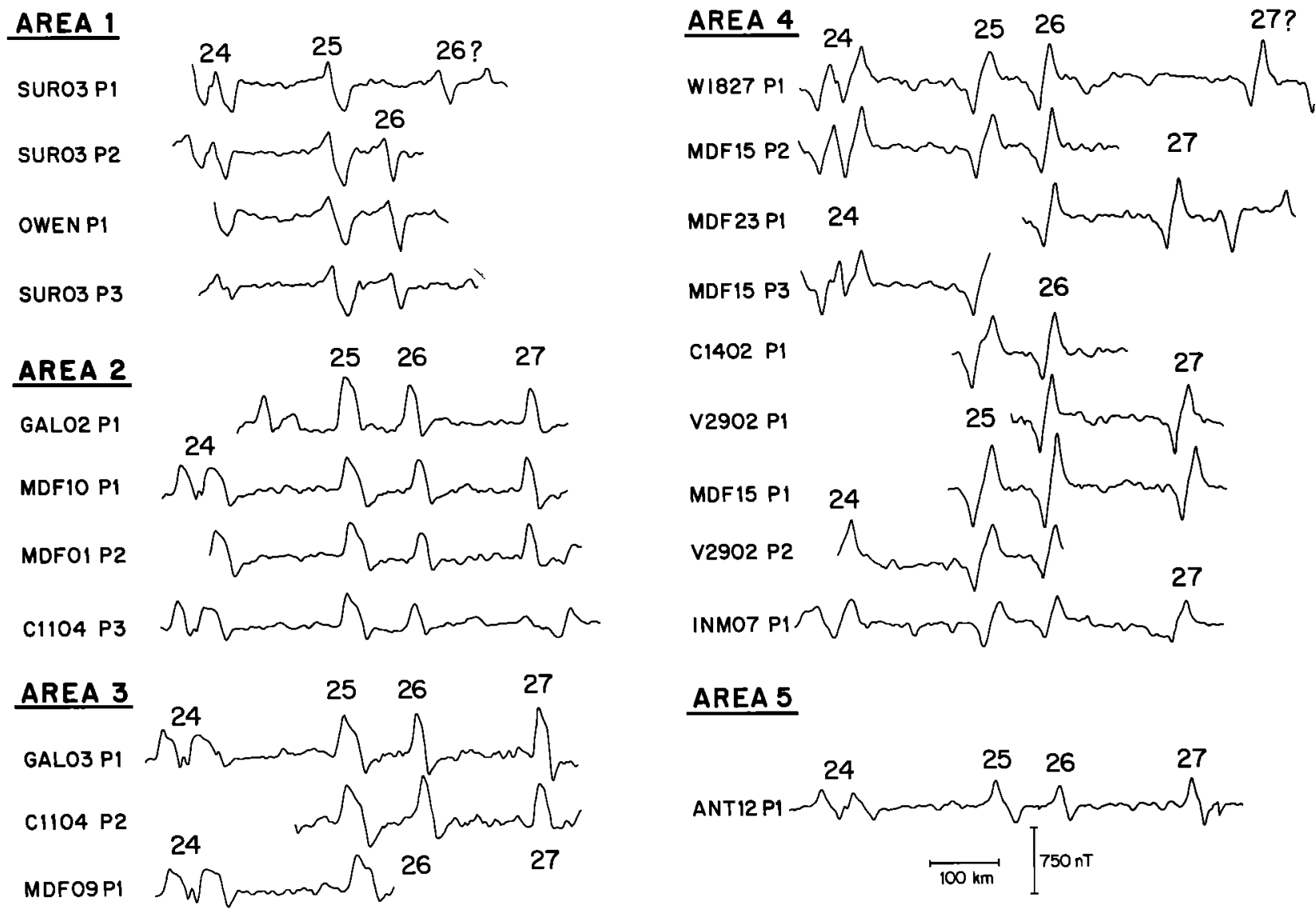

Fig. 3. Magnetic profiles crossing anomalies 24 to 27 from five regions of the Indian Ocean. Location of profiles shown in Figure 2.

In Figure 8, the profiles between anomalies 26 and 27 in the Indian Ocean, North Pacific and southeast Pacific are stretched to a common distance and compared. It is clear that the continuous pattern of tiny wiggles observed in the Indian Ocean profile is also observed in the southeast Pacific profile, with some additional shorter wavelength anomalies on the faster spreading rate profile. The similarity in detail between profiles from the Indian Ocean and the southeast Pacific is compelling evidence that these tiny wiggles are due to variations in the paleomagnetic dipole field. The question that remains is what aspect of dipole field variation is being observed.

\section{Origin of TINY Wiggles: SHORT PolartTy INTERVals OR INTENSTTY FLUCTUATIONS?}

Generally, it has been assumed that tiny wiggles are records of short polarity intervals [Blakely and Cox, 1972; Blakely, 1974]. The "short event" model does an acceptable job of modeling tiny wiggles that are observed at a spreading rate of $54 \mathrm{~mm} / \mathrm{yr}$ in the Indian Ocean. In Figure 9 we have constructed a sequence of short polarity intervals that models the tiny wiggles observed between anomalies 26 and 27 in the Indian Ocean. The duration of the short polarity intervals in this model are either $9 \mathrm{kyr}$ or $18 \mathrm{kyr}$, corresponding to crustal blocks $0.5 \mathrm{~km}$ and $1 \mathrm{~km}$ wide, respectively, in the Indian Ocean. A magnetic model and the MDF23P1 profile from the Indian Ocean are shown in the second from the top line of Figure 9.

The same set of polarity intervals, however, does a poor job of modeling the character of the tiny wiggles observed on the C2107 profile from the southeast Pacific (top line of Figure 9). At the ultrafast spreading rate, where we expect to have the highest temporal resolution, the tiny wiggles synthesized by the model form discrete, narrow anomalies that are often too spikey to match the more continuous character of the observed tiny wiggles. The character of the observed profile can be matched, of course, by inserting additional and shorter polarity intervals into the model. However, the exceedingly large number of reversals required to match the character of the ultrafast spreading rate profile requires that the reversal frequency in the early Cenozoic was many times greater than recognized from magnetostratigraphic studies [e.g., Lowrie et al., 1982]. In addition, the durations of the shortest polarity intervals are approaching the time it takes for the field to reverse (e.g., ca. $6 \mathrm{kyr}$ ) [Clement and Kent, 1987], implying there is insufficient time for the geomagnetic field to occupy the opposite polarity state.

The alternative model that we prefer is that tiny wiggles are a continuous record of paleointensity variations of Earth's magnetic field. Cande and LaBrecque [1974] showed that the tiny wiggles within anomaly 5 and between anomalies 12 and 13 in the North Pacific could be attributed to long period (100 to $250 \mathrm{kyr}$ ) variations in the intensity of the paleomagnetic field. A difficulty with their model was that such long periodicities required an implausibly long memory for dynamo processes. Here we will present a modification of the paleointensity model of Cande and LaBrecque [1974] and suggest that tiny wiggles are a filtered component of broad spectrum intensity variations compatible with observations of paleointensity of the field over the last $5 \mathrm{Ma}$.

A compilation of paleointensity data by McFadden and McElhinny [1982] showed that over the last $5 \mathrm{Ma}$ the dipole field intensity has fluctuated about the mean with a standard deviation of $42 \%$ of the mean over characteristic time scales of $10 \mathrm{kyr}$ and longer. In Figure 9 (bottom) we have simulated this field behavior by using a Gaussian random number generator to model horizontal variations in the magnetization of the source layer. Independent values were assigned to the source layer every $0.5 \mathrm{~km}$, corresponding in the Indian Ocean to a time interval of $9 \mathrm{kyr}$. The values were distributed with a $42 \%$ 


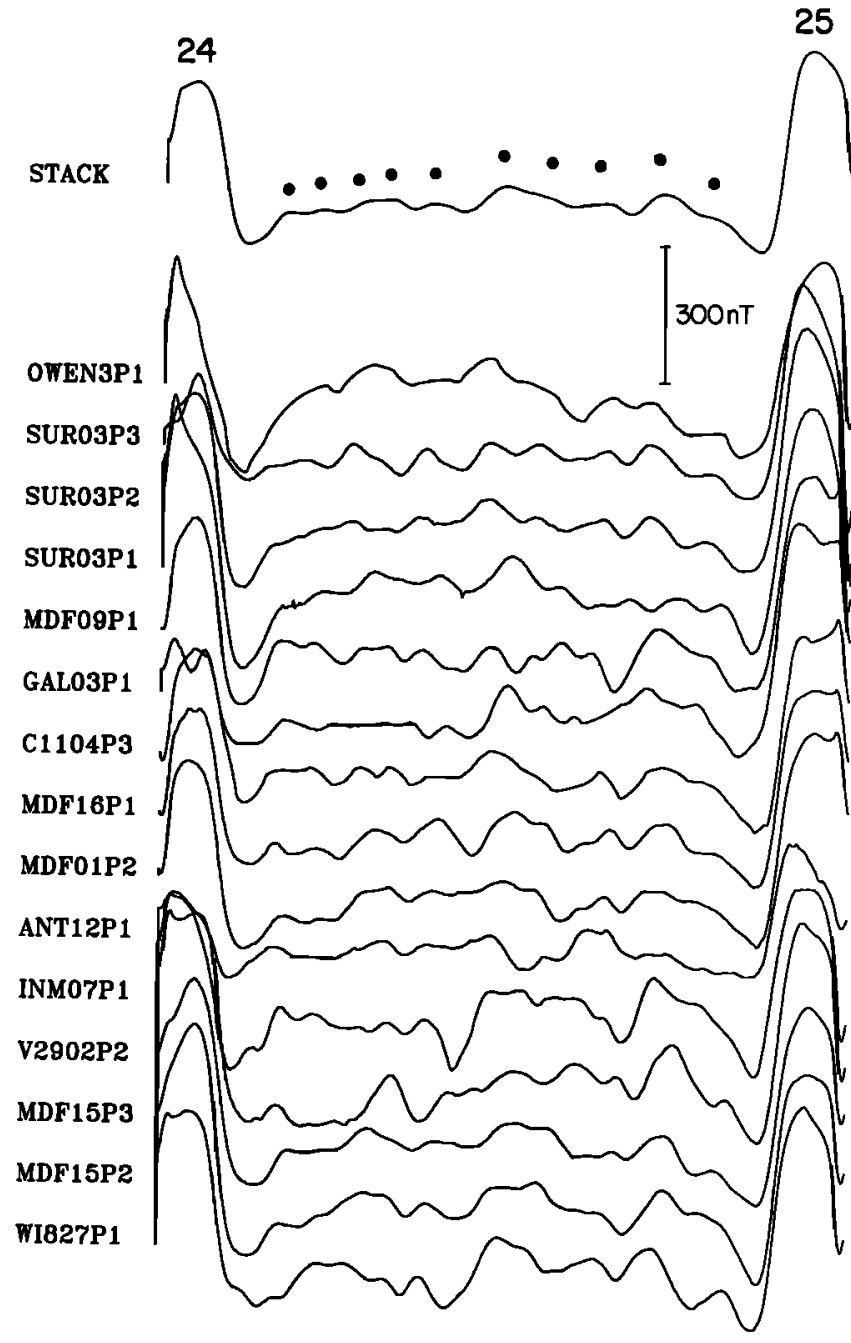

Fig. 4. Tiny wiggles on magnetic profiles crossing the reversed interval between anomalies 24 and 25 . The profiles have been stretched to a common width, reduced to the pole and their amplitudes normalized. A stack of the profiles is shown on the top line. Dots above the stack indicate location of 10 coherent tiny wiggles.

standard deviation about the mean magnetization. Note that the distribution of magnetization values is actually skewed slightly to the high side since values less than zero are truncated. The short wavelength variations in the source layer are earth filtered to produce a model profile corresponding to the spreading rate in the Indian Ocean (Figure 9, lowermost profile). For the faster spreading rate in the southeast Pacific, the model was stretched so that magnetic source layer has an independent magnetization value every $0.7 \mathrm{~km}$, preserving the same temporal sampling interval (Figure 9, second to lowermost profile).

Even though the exact pattern cannot be duplicated because the magnetization distribution is generated by a Gaussian process, the synthetic anomalies in Figure 9 (bottom) closely match the character of the observed tiny wiggles between anomalies 26 and 27 in two critical features. First, because of the bandpassing effect of the earth filter, the observed wavelengths at the sea surface are always in the range of 8 to $25 \mathrm{~km}$, corresponding to apparent periodicities (at a spreading rate of $54 \mathrm{~mm} / \mathrm{yr}$ ) of $150 \mathrm{kyr}$ to $450 \mathrm{kyr}$. Second, at faster spreading rates, the observed wavelengths (still 8 to $25 \mathrm{~km}$ ) correspond to shorter apparent periodicities, thus revealing a higherresolution version of the paleointensity variations.

A key virtue of the paleointensity model for tiny wiggles is that it requires no special attribute of paleomagnetic field

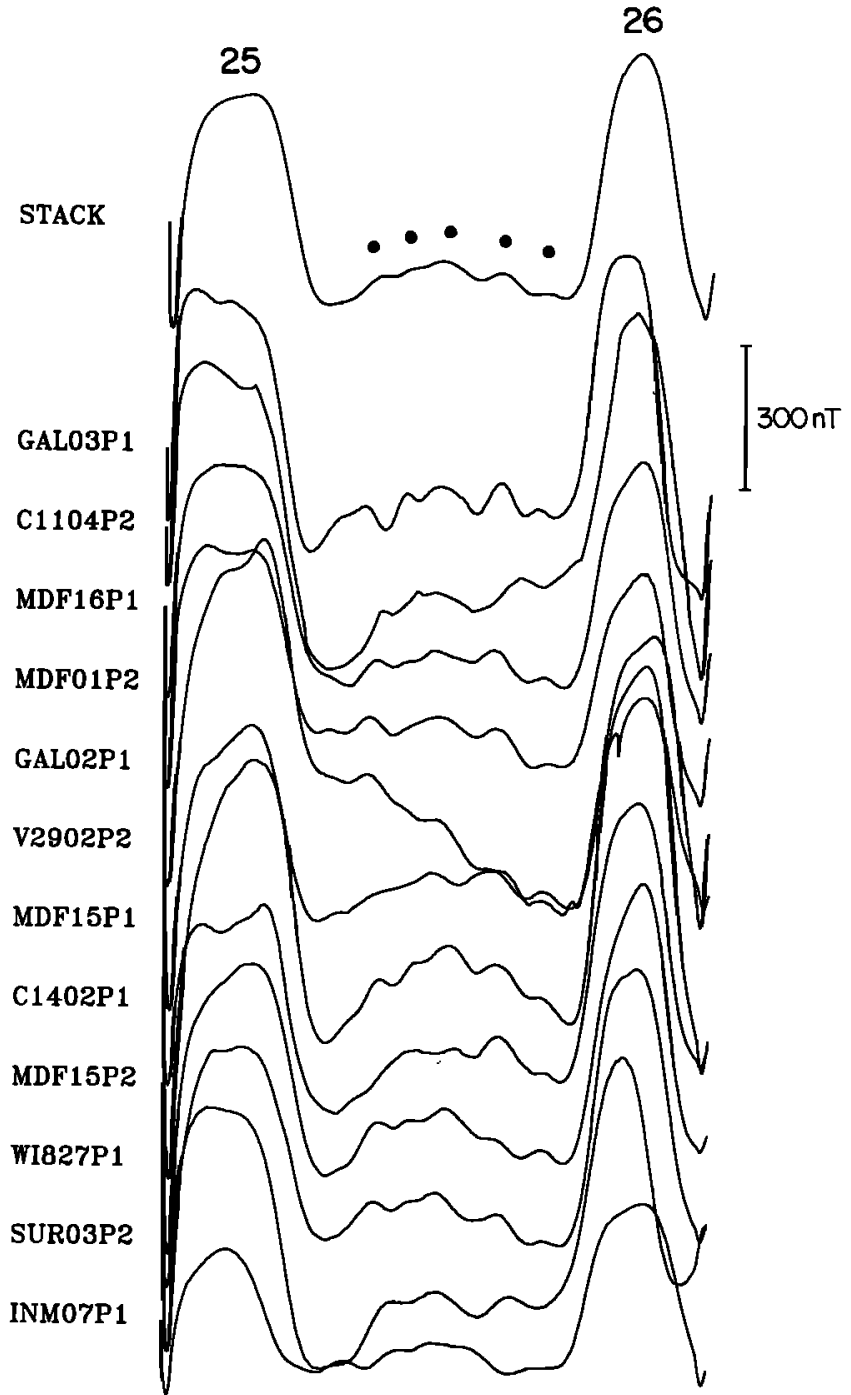

Fig. 5. Tiny wiggles on magnetic profiles crossing the reversed interval between anomalies 25 and 26 . The profiles have been processed as described in Figure 4. Dots above the stack indicate location of five coherent tiny wiggles.

behavior. The rate of reversals does not need to be dramatically increased with the insertion of a dense sequence of very short polarity intervals for which there is no independent, magnetostratigraphic evidence. Instead, our nominal model only requires that the frequency and amplitude of field intensity variations in the Paleocene are similar to those that are documented to characterize the geomagnetic field for the last 5 Ma. Our magnetic models indicate that if the ocean crust can record short polarity intervals with high fidelity it should also record paleointensity variations. In fact, we would argue that it probably requires less fidelity to record broadband paleointensity variations than to record discrete polarity intervals of only $10 \mathrm{kyr}$ duration. If tiny wiggles are only a record of discrete polarity intervals, what has happened to the paleointensity variations?

\section{Discussion}

It is clear that some coherent, small wavelength anomalies are due to short polarity intervals. Short polarity intervals with durations of around $30 \mathrm{kyr}$, such as the Reunion subchron between chrons 2 and 2A [Gromme and Hay, 1971], show up clearly on magnetic anomaly profiles on the East Pacific Rise [Rea and Blakely, 1975]. Shorter polarity intervals, such as the 


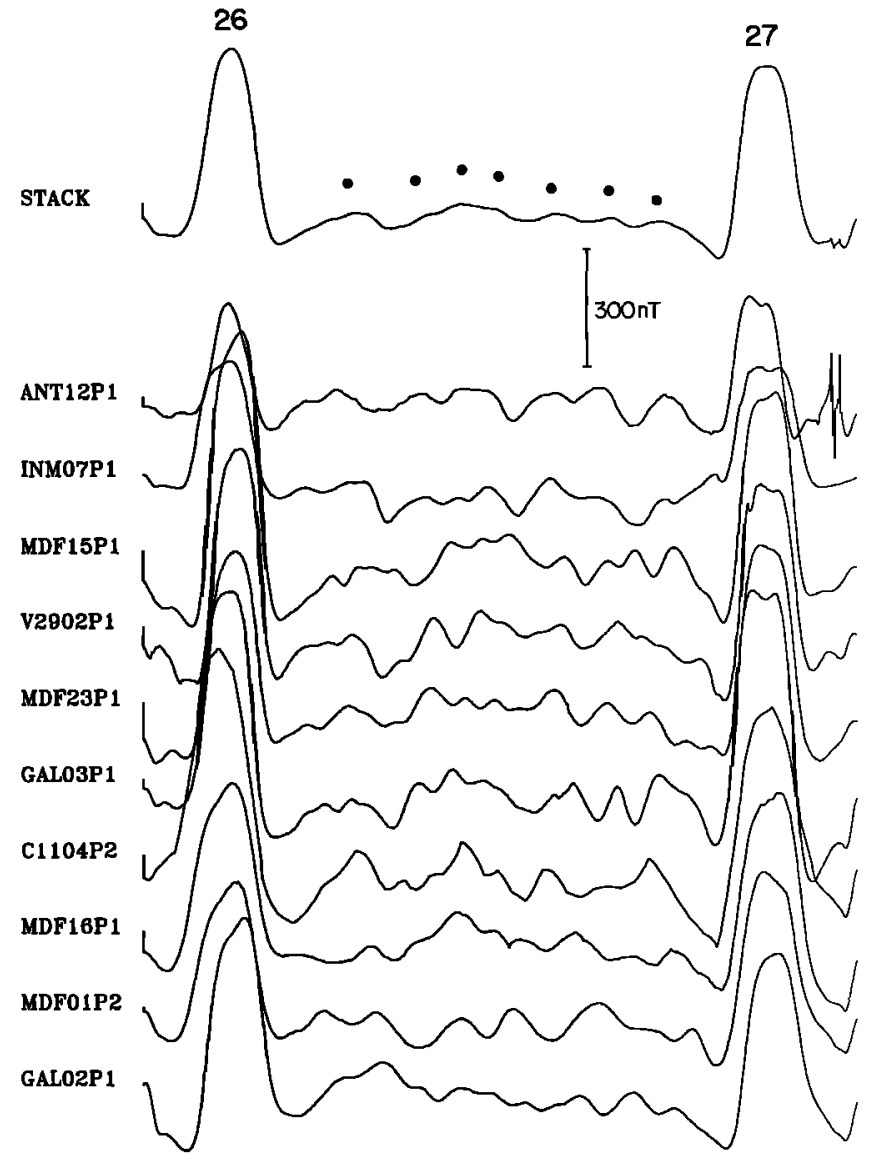

Fig. 6. Tiny wiggles on magnetic profiles crossing the reversed interval between anomalies 26 and 27 . The profiles have been processed as described in Figure 4. Dots above the stack indicate location of seven coherent tiny wiggles.
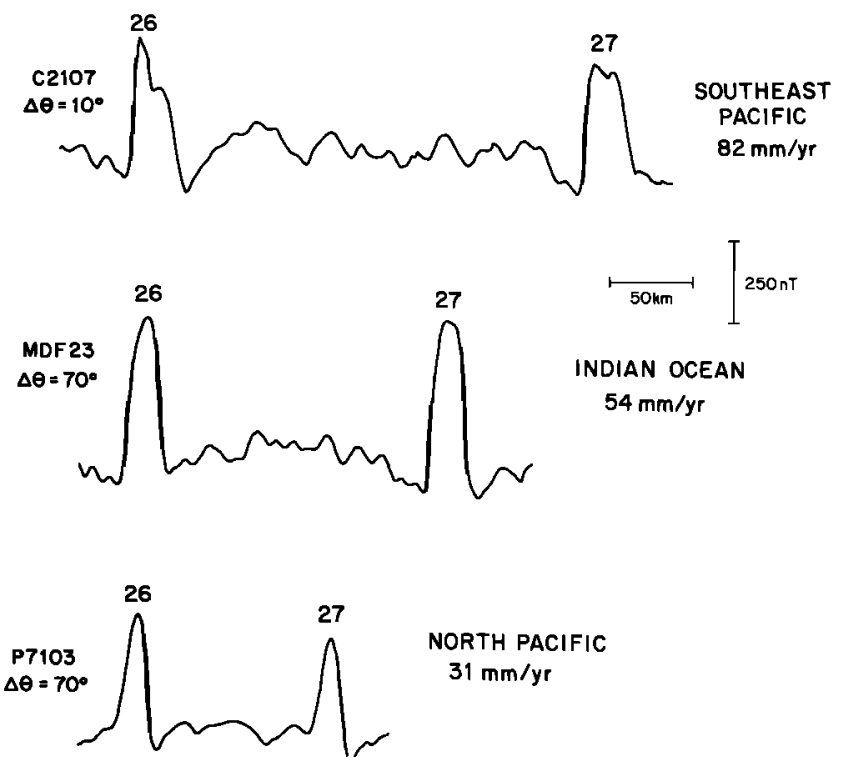

Fig. 7. An ultrafast spreading record of the reversed interval between anomalies 26 and 27 from the southeast Pacific (top). compared to representative profiles from the Indian Ocean (center) and the North Pacific (bottom). All three profiles have been reduced to the pole and normalized in amplitude. Cruise identifications are: prefix C: R/V Conrad; MDF: Marion Dufresne; P: Pioneer.
Cobb Mountain subchron between the Jaramillo and chron 2 [Mankinen et al., 1978; Mankinen and Gromme, 1982], thought to be of roughly $10 \mathrm{kyr}$ duration based on magnetostratigraphic studies [Clement and Kent, 1987], also can be observed in magnetic profiles although identification is more tenuous [Rea and Blakely, 1975]. The small wavelength anomalies associated with both of these polarity subchrons, however, could also be simulated by the paleointensity variation model. Thus discriminating between a reversal or paleointensity origin for short-wavelength anomalies ultimately requires confirming magnetostratigraphic evidence.

Nevertheless, the similarity in character of the tiny wiggles between anomalies 24 and 27 with the tiny wiggles observed within anomaly 5 and between anomalies 12 and 13 [Blakely, 1974; Cande and LaBrecque, 1974] leads us to speculate that the paleomagnetic field behavior responsible for most tiny wiggles is paleointensity variations. In particular, when observed at faster spreading rates, the same time interval is characterized by a larger number of tiny wiggles. This is clearly seen in Figure 9 in the comparison of anomalies 26 to 27 from the North Pacific $(31 \mathrm{~mm} / \mathrm{yr})$, Indian Ocean $(54 \mathrm{~mm} / \mathrm{yr})$, and the southeast Pacific $(82 \mathrm{~mm} / \mathrm{yr})$. Similarly, anomaly 5 , which was shown by Blakely [1974] to include four small scale anomalies in the North Pacific $(\sim 35 \mathrm{~mm} / \mathrm{yr})$, was shown by Cande and LaBrecque [1974] to consist of at least twice that number of tiny wiggles on the ultrafast spreading East Pacific Rise $(\sim 80 \mathrm{~mm} / \mathrm{yr})$. Although an ultrafast spreading rate record of anomalies 12 to 13 has yet to be found, even in the moderately fast spreading rate North Pacific profiles, Cande and LaBrecque [1974] recognized eight tiny wiggles in an interval of approximately 2 m.y. While there is evidence for some additional short polarity intervals that may correspond to a few of the tiny wiggles [e.g., McDougall et al. [1984] in anomaly 5, Hartl and Tauxe [1991] between anomalies 12 and 13, and Gee et al. [1991] between anomalies 24 and 25 ), associating all tiny wiggles to short polarity intervals would require an increase in reversal frequency many times that established from conventional magnetic polarity time scales. In addition, the character of tiny wiggles, where they have been best documented superimposed on anomaly 5 , between anomalies 12 and 13 , and between anomalies 24 to 27, does not seem to vary over the Cenozoic, while the average frequency of established reversals varies by a factor of three or more [Lowrie and Kent, 1983; McFadden and Merrill, 1984]. This implies to us that tiny wiggles represent a uniform, background variation of the geomagnetic field. If tiny wiggles are attributed to complete reversals of the field, they represent short periods of one polarity embedded in much longer periods of opposite polarity. Such a phenomenon can be likened to a monostable oscillator [Cande and LaBrecque, 1974] in contrast to the generally Poisson distributed nature of established geomagnetic reversals [Cox, 1968; McFadden and Merrill, 1984]. We believe a more plausible explanation for the consistent character of tiny wiggles is that they represent an earth-filtered record of a broad spectrum of paleointensity variations.

As a consequence of the inherent ambiguity in interpretation of tiny wiggles, short polarity intervals which are identified solely on the basis of marine magnetic anomaly data should be treated with a great deal of caution. It is always possible and often convenient to model the observed tiny wiggles as if they were due to short polarity intervals. Such a procedure is useful to specify the age and apparent duration of a candidate short polarity interval for magnetostratigraphic testing, and as a practical matter, to construct more detailed magnetic models that aid in the identification of problematic anomaly sequences. However, in order to emphasize the uncertain origin of tiny wiggles, we proposed the designation cryptochron for short polarity intervals that are modeled only from magnetic anomalies and that have apparent durations of less than $30 \mathrm{kyr}$ in the calibrated time scale [Cande and Kent, 1992]. With confirming magnetostratigraphic evidence a cryptochron can be elevated to the status of a polarity subchron, such as for the 


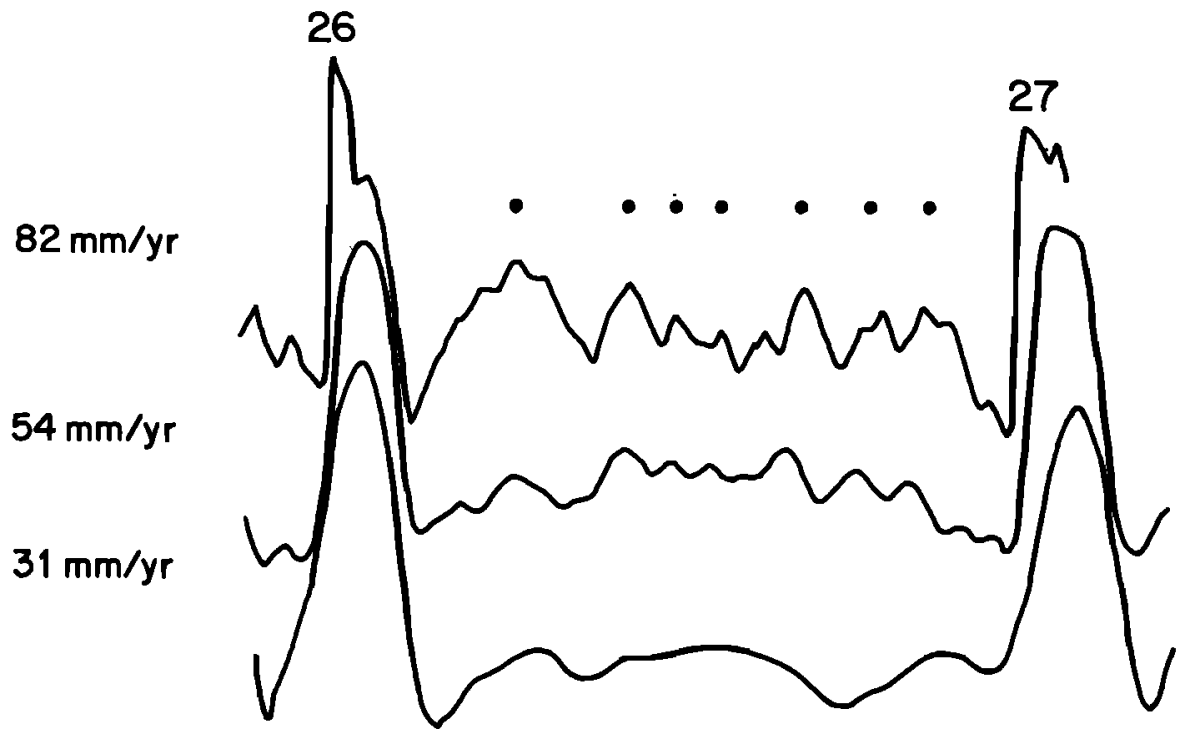

$\int_{0}^{250} n T$

SOUTHEAST PACIFIC $\stackrel{\longmapsto}{25 \mathrm{~km}}$

INDIAN OCEAN

$25 \mathrm{~km}$

NORTH PACIFIC

Fig. 8. Comparison of the tiny wiggles between anomalies 26 and 27 on the three profiles from Figure 7, after stretching to a common width. Note the remarkable similarity in detail of the tiny wiggles on the profiles from the Southeast Pacific and Indjan Ocean, confirming that they are a record of dipole field fluctuations in the Paleocene.

Cobb Mountain. In Table 1 we present the ages and apparent durations of the short polarity intervals (cryptochrons) that model the tiny wiggles between anomalies 24 and 27 in the Indian Ocean. Note that the age of the major anomalies are taken from the revised time scale of Cande and Kent [1992].

The selection of a $30 \mathrm{kyr}$ cutoff for the designation cryptochron reflects our feeling that most tiny wiggles which can be modeled with short polarity intervals of less than $30 \mathrm{kyr}$ duration, such as all of the tiny wiggles between anomalies 24 and 27, are likely to be due to paleointensity variations. It also seems likely that most tiny wiggles which can be modeled by short polarity intervals longer than $30 \mathrm{kyr}$ are likely to be due to true polarity intervals. However, the inherent ambiguity in their interpretation must be recognized by noting that it is possible that some tiny wiggles modeled by short polarity intervals approaching $50 \mathrm{kyr}$ are conceivably due to paleointensity variations. A second reason for selecting $30 \mathrm{kyr}$ as a cutoff for the designation cryptochron is that for durations shorter than $30 \mathrm{kyr}$ the marine magnetic anomaly record has been investigated in detail over only a few relatively discrete time intervals.

\section{CONCLUSIONS AND IMPLICATIONS}

Tiny wiggles are observed as a ubiquitous background on fast and ultrafast spreading rate profiles and appear to contain a unique, high-resolution recording of the geomagnetic dipole field. The type of field behavior recorded in the tiny wiggles cannot be unambiguously determined from sea surface magnetic profiles. However, indirect arguments suggest that the tiny wiggles are, in general; a record of continuous variations in the paleointensity of the field.

The paleointensity model for tiny wiggles has several implications:

1. Because tiny wiggles reflect a continuous high-resolution recording of the geomagnetic field they may provide a unique window for analyzing the temporal evolution of the geomagnetic dynamo. It would be interesting to compare the character of tiny wigglès in the Cretaceous quiet zones, which formed during a long time interval of apparently no reversals, to the Cenozoic record. Differences, including the absence of tiny wiggles in the Cretaceous quiet zones, could be related to current ideas relating secular variation and the origin of geomagnetic polarity reversals [Merrill and McFadden, 1988].
TABLE 1. Cryptochrons From C24 to C27
Interval, Ma

53.462

53.604

53.821

53.967

54.170

54.490

54.739

54.963

55.071

55.309

55.611

56.827

57.002

57.160

$\mathbf{5 7 . 4 2 6}$

57.586

58.756

59.382

59.612

59.821

60.261

60.638

60.931

\begin{tabular}{ll}
- & $\mathbf{6 3 . 4 7 1}$ \\
\hline & $\mathbf{5 3 . 6 1 3}$ \\
- & $\mathbf{5 3 . 8 3 0}$ \\
- & $\mathbf{5 3 . 9 7 6}$ \\
- & $\mathbf{5 4 . 1 8 0}$ \\
- & $\mathbf{5 4 . 5 0 0}$ \\
- & $\mathbf{5 4 . 7 4 9}$ \\
- & $\mathbf{5 4 . 9 6 3}$ \\
- & $\mathbf{5 5 . 0 8 1}$ \\
- & $\mathbf{5 5 . 3 1 9}$ \\
- & $\mathbf{5 6 . 6 2 2}$ \\
- & $\mathbf{5 6 . 8 4 5}$ \\
- & $\mathbf{5 7 . 0 2 0}$ \\
- & $\mathbf{5 7 . 1 6 9}$ \\
- & $\mathbf{5 7 . 4 3 5}$ \\
- & $\mathbf{5 7 . 6 0 4}$ \\
- & $\mathbf{5 8 . 7 7 7}$ \\
- & $\mathbf{6 9 . 4 0 3}$ \\
- & $\mathbf{5 9 . 6 2 2}$ \\
\hline & $\mathbf{5 9 . 8 3 2}$ \\
\hline & $\mathbf{6 0 . 2 8 2}$ \\
\hline & $\mathbf{6 0 . 6 4 8}$ \\
\hline & $\mathbf{6 0 . 9 4 1}$
\end{tabular}

Cryptochron

C24r-1

C24r-2

C24r-3

C24r-4

C24r-5

C24r-6

C24r-7

C24r-8

C24r-9

C24r-10

C24r-11

C25r-1

C25r-2

C25r-3

C25r-4

C25r-5

C26r-1

C26r-2

C26r-3

C26r-4

C26r-5

C26r-6

C26r-7
2. Our model provides an alternative interpretation for the small scale anomalies that have been mapped within the Pacific Jurassic quiet zone and regarded as reflecting frequent field reversals [e.g., Cande et al., 1978; Handschumacher et al., 1988; Nakanishi et al., 1989]. In Figure 10 we compare the tiny wiggles between anomalies 26 and 27 in the southeast Pacific to the small scale anomalies between anomalies M25 and M29 on the Japanese lineations in the Pacific, two areas that formed at nearly the same high spreading rate. The similarity in character is striking, suggesting a common origin related to paleointensity variations. Small-scale anomalies have also been observed over short distances within the 
(1) SHORT POLARITY INTERVALS
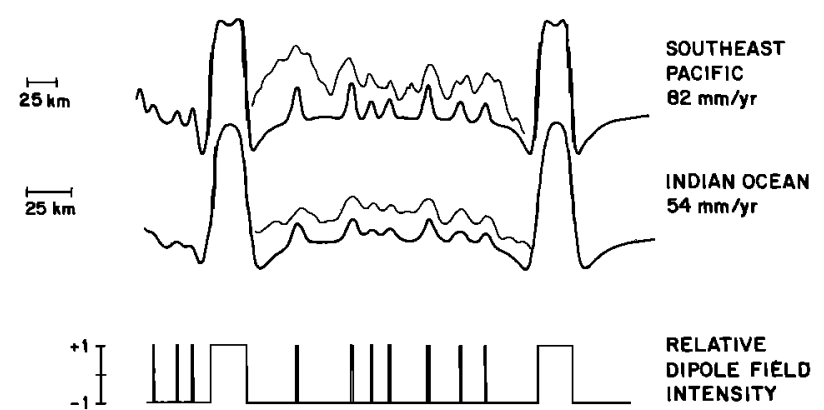

(2) INTENSITY FLUCTUATIONS

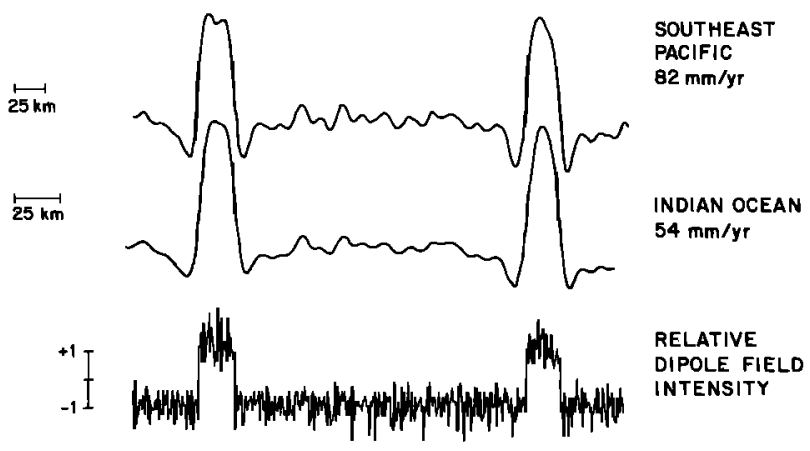

Fig. 9. Comparison of two basic models for the source of the tiny wiggles between anomalies 26 and 27 . The top set of models assume the tiny wiggles are due to short intervals ( $9 \mathrm{kyr}$ to $18 \mathrm{kyr}$ ) of normal polarity. The light-weight profiles drawn above the model profiles are traces of the representative profiles shown in figures 7 and 8 . The lower set of models assume the tiny wiggles are caused by random fluctuations in the paleointensity of the dipole field in the Paleocene with a temporal variation compatible with the observed intensity variations over the last 5 Ma. The lower set of models better simulate the character of the observed tiny wiggles.

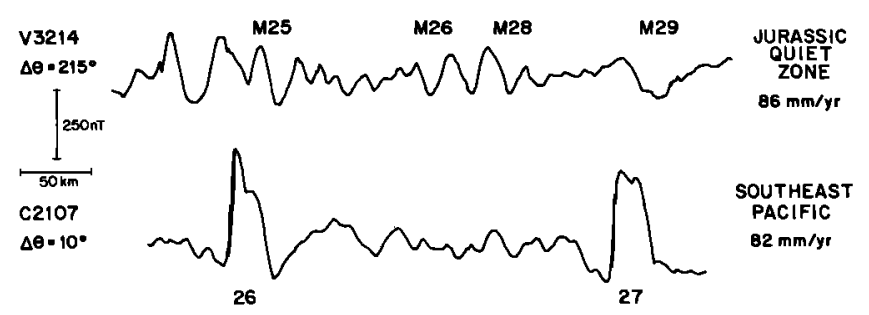

Fig. 10. A comparison of magnetic profiles across anomalies M25 to M29 on the Japanese lineations in the Pacific Jurassic quiet zone (top) and Pacific-Aluk anomalies 26 to 27 in the southeast Pacific (bottom). The similarity in character of the small-scale anomalies older than M25 to the tiny wiggles between anomalies 26 and 27 suggests that the pre-M25 anomalies are also due to paleo-intensity variations. Cruise identifications: prefix C: R/N Conrad; V: R/V Vema.

Cretaceous quiet zone in the Central Atlantic [Vogt and Johnson, 1971] and may also reflect paleointensity variations.

3. Like the distinctive patterns formed by the "random" reversals of the magnetic field, "random" intensity variations should also form distinctive patterns. Tiny wiggles therefore represent potential time markers over large regions of uniform crustal polarity such as the Cretaceous quiet zones.
4. Much of the variance observed in magnetic anomaly profiles, particularly at fast spreading rates, comes from paleointensity fluctuations in the dipole field. Studies that infer attributes of the crustal emplacement process based on the character of marine magnetic anomalies (e.g., Schouten and Denham type models) need to remove the contribution to the variance that comes from the dipole field variations before analyzing the emplacement process.

Acknowledgements. We would like to thank Rick Blakely, Pat Taylor, and an anonymous reviewer for their helpful and constructive comments. This study benefited greatly from the inclusion of several profiles collected by Roland Schlich and his colleagues at EOPG Strasbourg These data were obtained as part of a joint U.S.-French Indian Ocean data compilation project supported by NSF grant OCE86-19862. Additional support was provided by NSF grant OCE91-04447. Lamont-Doherty Geological Observatory contribution \#4952.

\section{REFERENCES}

Arkani-Hamed, J., Thermoviscous remanent magnetization of the oceanic lithosphere inferred from its thermal evolution, J. Geophys. Res., 94, 17,421-17,436, 1989.

Blakely, R. J., Geomagnetic reversals and crustal spreading rates during the Miocene, J.Geophys. Res., 79, 2979-2985, 1974.

Blakely, R. J., and A. Cox, Evidence for short geomagnetic polarity intervals in the early Cenozoic, J. Geophys. Res., 77. 7065-7072, 1972.

Cande, S. C., A paleomagnetic pole from late Cretaceous marine magnetic anomalies in the Pacific, Geophys. J. R. Astron. Soc., 44, 547-566, 1976.

Cande, S. C., Anomalous behaviour of the paleomagnetic field inferred from the skewness of anomalies 3 and 34, Earth Planet. Sci. Lett., 40, 275-286, 1978

Cande, S. C., and D. V. Kent, Constraints imposed by the shape of marine magnetic anomalies on the magnetic source, $J$. Geophys. Res., 81, 4157-4162, 1976.

Cande, S. C., and D. V. Kent, A new geomagnetic polarity time scale for the late Cretaceous and Cenozoic, J. Geophys. Res., in press, 1992.

Cande, S. C., and J. L. LaBrecque, Behaviour of the Earth's paleomagnetic field from small scale marine magnetic anomalies, Nature, 247, 26-28, 1974.

Cande, S. C., E. Herron, and B. Hall,The early Cenozoic tectonic history of the Southeast Pacific, Earth Planet Sci. Lett., 57, 63-74, 1982.

Cande,S. C., J. L. LaBrecque, and R. L. Larson, Magnetic anomalies in the Pacific Jurassic Quiet Zone, Earth Planet. Sci. Lett., 41, 434-440, 1978.

Clement, B. M., and D. V. Kent, Short polarity intervals within the Matuyama: Transitional field records from hydraulic piston core sites in the North Atlantic, Earth Planet. Sci. Lett., 81, 253-264, 1987.

Cox, A., Lengths of geomagnetic polarity intervals, J. Geophys. Res., $73,3247-3260,1968$.

Gee, J., C. T. Klootwijk, and G. M. Smith, Magnetostratigraphy of Paleogene and Upper Cretaceous sediments from Broken Ridge, Eastem Indian Ocean, edited by J. Weissel et al., Proc. Ocean Drill. Program Sci. Results, 121, 359-376, 1991.

Gromme, C. S., and R. L. Hay, Geomagnetic polarity epochs: Age and duration of the Olduvai normal polarity event, Earth Planet. Sci. Lett., 10, 179-185, 1971.

Handschumacher, D., W. W. Sager, T. W. C. Hilde, and D. R. Bracey, Pre-Cretaceous tectonic evolution of the Pacific plate and extension of the geomagnetic polarity reversal timescale with implications for the origin of the Jurassic "Quiet Zone," Tectonophysics, 155, 365$380,1988$.

Hartl, P., and L. Tauxe, Comparison of a high resolution sedimentary record with marine magnetic anomalies 12 and 13 (abstract), Eos Trans. AGU, 72 (44), Fall Meeting, Suppl., 135, 1991.

Heirtzler, J. R., G. O. Dickson, E. M. Herron, W. C. Pitman III, and X. LePichon, Marine magnetic anomalies, geomagnetic field reversals, and motions of the ocean floor and continents, J. Geophys. Res., 73, 2119-2136, 1968.

LaBrecque, J. L., D. V. Kent, and S. C. Cande, Revised magnetic polarity timescale for late Cretaceous and Cenozoic time, Geology, 5, 330-335, 1977.

Lowrie,W., and D. V. Kent, Geomagnetic reversal frequency since the Late Cretaceous, Earth Planet. Sci. Lett., 62, 305-313, 1983.

Lowrie, W., W. Alvarez, G. Napleone, K., Perch-Nielsen, I. Primoli Silva, and $M$. Toumarkine, Paleogene magnetic stratigraphy in 
Umbrian pelagic carbonate rocks: The Contessa sections, Gubbio, Geol. Soc. Am., 93, 414-432, 1982.

Mankinen, E. A., and C. S. Gromme, Paleomagnetic data from the Coso Range, California, and the current status of the Cobb Mountain normal geomagnetic event, Geophys. Res. Lett., 9, 1279-1282, 1982.

Mankinen, E. A., J. M. Donnelly, and C. S. Gromme, Geomagnetic polarity event recorded at 1.1 m.y. B.P. on Cobb Mountain, Clear Lake volcanic field, California, Geology, 6, 653-656, 1983, 1978.

McDougall, I., L. Kristjansson, and K. Saemundsson, Magnetostratigraphy and geochronology of northwest Iceland, J. Geophys. Res., 89, 7029-7060, 1984.

McFadden, P. L., and M. W. McElhinny, Variations in the geomagnetic dipole, 2: Statistical analysis of VDM's for the past 5 million years, J. Geomagn. Geoelectr., 34, 163-189, 1982.

McFadden, P. L., and R T. Merrill, Lower mantle convection and geomagnetism, J. Geophys. Res., 89, 3354-3362, 1984.

Merrill, R., and M. McElhinny, The Earth's Magnetic Field, 401 pp., Academic, San Diego, Calif., 1983.

Merrill, R. T., and P. L. McFadden, Secular variation and the origin of geomagnetic field reversals, $J$. Geophys. Res., 93, 11,589-11,598, 1988.

Molnar, P., F. Pardo-Casis, and J. Stock, Uncertainties in the reconstructions of the Indian, African and Antarctic plates since late Cretaceous time, Basin Res., 1. 23-40, 1988.

Nakanishi, M., K. Tamaki, and K. Kobayashi, Mesozoic magnetic anomaly lineations and seafloor spreading history of the northwestern Pacific, J. Geophys, Res., 94, 15,437-15,462, 1989.

Patriat, P., Reconstitution de l'evolution du systeme de dorsales de l'ocean Indien par les methodes de la Cinematique des Plaques, Doctoral d'Etat, Univ. Paris 6. Paris, 1983.

Petronotis, K. E., R. G. Gordon, and G. D. Acton, Palaeomagnetic poles with a fine time resolution: A Chron 25r (56.5 - 57.5 Ma) Pacific plate pole determined from shape analysis of marine magnetic anomalies (abstract), Eos Trans. AGU, 70, 1064, 1989.

Raymond, C. A., and J. L. LaBrecque, Magnetization of the oceanic crust: thermoremanent magnetization or chemical remanent magnetization?, J. Geophys. Res., 92, 8077-8088, 1987.
Rea, D. K., and R. J. Blakely, Short-wavelength magnetic anomalies in a region of rapid seafloor spreading, Noture, 255, 126-128, 1975.

Roest, W. R., J. Arkani-Hamed, and J. Verhoef, The seafloor spreading rate dependence of the anomalous skewness of marine magnetic anomalies, Geophys. J. Inter., 109, 653-669, 1992.

Royer, J.-Y., and M. F. Coffin, Jurassic to Eocene plate tectonic reconstructions in the Kerguelen plateau region, Leg 120, Proc. Ocean Drill. Program Sci. Results, 120, 917-930, 1992.

Schneider, D. A., and D. V. Kent. Testing models of the Tertiary paleomagnetic field, Earth Planet. Sci. Lett, 101, 260-271, 1990.

Schouten, J. A., A fundamental analysis of magnetic anomalies over oceanic ridges, Mar. Geophys. Res., 1, 111-144, 1971.

Schouten, H., and C. Denham, Modeling the oceanic magnetic source layer, in Deep Sea Drilling Results in the Allantic Ocean: Ocean Crust, Maurice Ewing Ser., Vol. 2, edited by M. Talwani, C. G.Harrison, and D. E. Hayes, p. 151-158, AGU, Washington, D. C. 1979.

Schouten, H., and K. McCamy, Filtering marine magnetic anomalies, $J$. Geophys. Res., 77, 7089-7099, 1972.

Verosub, K. L., and E. M. Moores, Toctonic rotations in extensional regimes and their paleomagnetic consequences for oceanic basalts, $J$. Geophys. Res., 86, 6335-6349, 1981.

Vogh, P. R, and G. L. Johnson, Cretaceous seafloor spreading in the western North Atlantic, Nature, 234, 22-25, 1971.

Wilson, D. S. and R. N. Hey, The Galapagos axial magnetic anomaly: evidence for the emperor event within the Brunhes and for a two-layer magnetic source, Geophys. Res. Lett., 8, 1051-1054, 1981.

S. C. Cande and D.V. Kent, Lamont-Doherty Geological Observatory of Columbia University, Palisades, NY 10964.

(Received January 6, 1992; revised May 8, 1992;

accepted May 12, 1992.) 